\title{
Significance, Principles and Methods of Cultural-input in the Teaching Process of Russian
}

\author{
Chen Binbin \\ Zunyi Normal College, Zunyi, Guizhou, China, 563002 \\ hunter2011@foxmail.com
}

Keywords: Russian teaching, Cultural-input, Significances, Principles and methods.

\begin{abstract}
Language is the most important tool for human communication, is a means for human beings to form and express ideas, is the most basic information carrier of the human society, and is the symbol system of the combination of sound and meaning of the social convention. Culture refers to the behavior and way of thinking that people learn, create and share in the same social group. The culture of a nation includes the national belief, behavior criterion, language, etiquette, art, technology, dress, religion and economic system. Language is a part of the culture; language teaching can't be separated from culture. This paper discusses the role, significance, principles and methods of cultural introduction in Russian language teaching.
\end{abstract}

\section{Introduction}

Language is the most important tool for human communication. People use language to preserve and transmit the achievements of human civilization. Language is one of the important characteristics of a nation, is a mirror of national culture, and is the carrier of national culture. Russian is no exception, like other languages, Russian is the crystallization of the wisdom of Russia, with distinct national cultural characteristics. The purpose of Russian learning is not only to master the internal basic knowledge of pronunciation, vocabulary, grammar, rhetoric and new expression method, but also the knowledge of Russian culture, politics, economy, history, military, national conditions, characters, customs and so on. Due to the factors of the disintegration of the former Soviet Union, the decline of Russia's international influence and the limitations of the use of Russian, Russian learning environment has deteriorated, students' interest in Russian learning has decreased, so it is of great advantage to improve the students' interest in learning and reduce the loss of Russian students when importing Russian culture timely, appropriately and moderately in Russian teaching.

\section{The Function and Significance of Cultural-input in Russian Teaching}

Language must be rooted in the cultural language environment. Culture is a complex social phenomenon. It is a complex of the past, reality and future of a nation. It is even more a fusion of many social and national aspects. This complicated social phenomenon just meets the young students' curiosity, and cultivate students' social cultural competence. The process of cultural-input is a process that students are familiar with the cultural phenomenon of the Russian national culture, which is also the cultural import process that establishes the Russian culture in their minds. The famous scholar, Mr. Wang Zuoliang, said in Introduction to European Culture, "the Chinese students who have learned English in reading English books and communicated with people in English speaking countries have often felt a lot of difficulties due to the lack of knowledge of European culture. If not quite understanding European cultural knowledge, they may not fully understand the books they are reading, and it is also difficult to have a smooth conversation. And once having a lot of knowledge of the culture, they can not only improve the understanding, but also learn the language better because of learning culture first before learning language." It is true to English learning and Russian learning is no exception, take the introduction of literature (literature is an important part of culture) as an example, in history, Russia appeared many literary masters. Russian literature occupies a place of world literature. As a carrier of the history and culture of Russia, Russian literature should be an important part of Russian learning. 
As the world classic works of literature leaving present, most of them are experienced the test of time and having graceful language and full of Russian culture color and historical features. Reading these literary works is good for students to obtain the necessary literature and cultural knowledge, and at the same time, a moderate amount of reading can help students to develop the "language sense", improve the students' ability of listening, speaking, reading and writing. Therefore, it is helpful to improve the students' level of Russian language if combine culture education into Russian language teaching. It will be beneficial for teachers' Russian teaching and students' Russian learning when combining necessary cultural education with the traditional Russian language teaching to promote Russian language teaching from a simple, examination oriented language to focus on improving the students' cultural quality to improve the students' level of Russian. Through the transformation of cultural-input, teachers improve their teaching level, enrich classroom content and improve their teaching enthusiasm and initiative, and carry out appropriate cultural education for students, their initiative and enthusiasm for Russian learning can be fully mobilized and promote students to learn Russian actively.

Because the purpose of Russian education is not only to make students master a language, it is more important to make the students recognize Russia, understand Russia and then study Russian to serve the political, economic, cultural, scientific and other services for Russian and our country. Cultural-input naturally becomes the objective requirements of Russian teaching since culture is the expression form, record form and communication form of all the nature and society like politics, economy, science, education and so on.

Language is the reflection of the objective world, and the differences between Chinese and Western cultures will inevitably lead to the differences of the language phenomena such as word meaning, sentence meaning, associative meaning and figurative meaning. Language is an inseparable part of the culture, only to master the language symbol system but ignore its culture, it will leads to the phenomenon of speaking Russian fleecily while making serious pragmatic mistakes. Therefore, to cultivate the students' ability to communicate, we must cultivate the students' social and cultural ability when carrying out language teaching. The cultural-input can stimulate students' interest and meet the requirements of their language learning, so as to promote the teaching of Russian language and have a positive effect on language learning.

College Russian text selection is rich for the contents include history, geography, society, humanities, value orientation and social concepts, which not only can stimulate students' learning motivation, but also can help students understand the text better and deepen the impression. And every aspect of Russian learning's listening, speaking, reading, writing and translating cannot be independent from mastering of cultural background knowledge, only in this way can students understand Russian more comprehensive and accurately.

\section{Some Important Principles of Cultural-input in Russian Teaching}

Principle of Systematization. Any teaching activity is a gradual process, cultural teaching is no exception. Teachers should determine the content of culture teaching according to the student's language proficiency, acceptance and understanding ability. It is generally believed that culturalinput is divided into primary, middle and advanced stages in practice. The primary stage mainly introduces the differences in daily life communication between Russian and Chinese mainstream culture, and embodied in the form and use of language, so as to enable students to master the ability of Russian language in daily life; The main content of the intermediate stage is to introduce the differences between Russian and Chinese words, idioms and usage caused by the cultural differences, so that students are familiar with Russian and Chinese semantic differences and indepth understanding of Russian expression method concerns the cultural connotation, so as to help them proper use these words in language communication; advanced stage mainly starting from the deep-seated differences between Chinese and Western cultures, modes of thinking, communicative relationship and verbal expression, in order to make students improve the ability of language expression, and further in-depth understanding of interpersonal relationship and communication mode of the west. 
Principle of Moderation. In Russian teaching process, we must input culture closely related to the cross culture communication instead of introducing much other culture which is regarded as the integration of art, music, history, geography, philosophy and so on, weakening the effect of language teaching. It must be clear that the cultural-input in Russian teaching is carried out in the framework of the Russian language teaching. Therefore, keep in mind that cultural-input in Russian teaching should not be a reversal of the order of host and guest.

Principle of Mainstream. The content of culture is very rich as well as extremely complex. Every culture contains different types of sub culture, for instance, due to regional differences, it could exist sub culture in the formation of eastern culture and western culture and because of different social strata, it forms middle class culture, culture of poverty, hippie culture and so on even in the same country. The teaching content is the common core in language teaching. The content of language teaching is the common language of the language, and cultural-input should be the common core of the culture (Russian Culture). Most of the language and nonverbal communication in Russian can be explained by the mainstream culture. Of course, all kinds of sub culture will have some impact on the communication, but after all, this proportion is too small to be the focus of cultural-input.

Principle of System. At present, maybe the biggest problem of cultural-input is the lack of system. Teachers give an explanation by the way when encountering a kind of cultural phenomenon in language teaching process, this kind of teaching is piecemeal and have no uniform and specific requirements of the contents and methods of culture teaching. Therefore, it is urgent to develop a cultural-input outline of Russian teaching. Such an outline can refer to the provisions and requirements of the basic stage and the high grade Russian teaching syllabus to make clear of the principle, content, method and way of culture teaching, as well as the requirements of the students' level they should achieve. In this way, Russian teaching can be based on the outline, and it can import every aspect of the communication culture and knowledge culture systematically, so as to avoid the blind and confusion in the process of cultural-input.

\section{Basic Methods of Cultural-input}

Select the Appropriate Materials. In order to meet the needs of social and cultural communication, it is necessary to add the contents of the national conditions, culture, customs and behavior patterns of Russian in the course of Russian teaching. Therefore, this requires us to choose materials with the main line of language skill training as well as rich in content and orderly in system and can provide students with the knowledge of the culture of the country. In addition, after the class, the students are recommended to read some cross cultural books to enhance their understanding of the cultural connotation when understanding and learning grammar knowledge. This cultivates students' cultural awareness and improves their intercultural communicative competence.

Enrich Teaching Means. In the process of teaching, we can make use of modern teaching methods such as pictures, audio recording, video, film and multimedia in addition to teaching the basic meaning of language, extended meaning and collocation relationship to deepen students' direct understanding of language knowledge, and to increase students' interest in understanding Russian and all Russian general national conditions.

Improve the Teachers' Cultural Accomplishment. In the process of language teaching, the introduction of cultural background knowledge has not become a "natural" habit, besides of the objective factors, the teacher's own cultural level is also a restriction factor. If the teachers themselves do not understand the culture well, then in the process of teaching, it seems more difficult and deliberately to introduce cultural knowledge. However, if teachers themselves are very understanding of Russian culture, then the introduction of cultural knowledge will be more natural. Therefore, teachers in the process of reaching and teaching must pay more attention to cultural knowledge and influence the students in a"subtle" way.

Strengthen Practice. The ultimate goal of foreign language learning is to communicate in that language smoothly. Therefore, students should be provided with more opportunities to practice, so 
that students can test their knowledge of language and culture in practice. For low grade students, social practice is not suitable, but we can set specific communicative situation in class for students to communicate with the knowledge they have mastered; and the high grade students, who already has a certain language knowledge and cultural background knowledge should be encourage to communicated with exchange students in or outside school to practice their language. College, school related associations can also carry out recreational activities related to exchange students to provide more opportunities for students to practice their foreign language.

\section{Conclusion}

In short, in the context of globalization, simple language teaching has been unable to adapt to the development and requirements of the times. More and more scholars have reached a consensus that language knowledge teaching and cultural background knowledge teaching are inseparable. This requires teachers to follow scientific principle, adopt scientific methods to establish students' consciousness of Chinese and Russian cultural differences, pay attention to the introduction of cultural background knowledge, and cultivate students' ability of cross-cultural communication in the course of Russian teaching. Only in this way can we cultivate the talents in Russian language with not only a solid knowledge of the language, but also good cross-cultural communication ability and cultural qualities.

\section{References}

[1] G.Y. Zhu, On Cultural-input and Russian Teaching, Modern Business Trade Industry, 8(2009)31-33.

[2] S.Q. Ruan, A Simple Analysis on Literal Culture Education and Public English Teaching in Science and Technology Higher Vocational College, Anhui Literature, 3(2009)12-15.

[3] Y.H. Li, Russian Cultural-input and Russian Teaching, Teacher, 19(2010)56-57.

[4] Y. Su, On Cultural-input in Russian Teaching, J., Journal of Inner Mongolia Normal University, 12(2010)27-29. 